\title{
EVALUATION OF THE MINERALIZING POTENTIAL OF ORAL FLUID IN CHILDREN WITH DOWN SYNDROME DEPENDING ON THE LEVEL OF THE CARIOGENIC PROCESS
}

\author{
Rosana Nazaryan ${ }^{1}$ \\ rosnazaryan@gmail.com \\ Liudmyla Kryvenko ${ }^{1}$ \\ milas003@gmail.com \\ Olga Iskorostenskaya \\ iskorostenskaov@gmail.com \\ Yelena Tishkovets \\ Department of Continuum mechanics and Strength of materials \\ National Technical University "Kharkiv Polytechnic Institute" \\ 2 Kyrpychova str., Kharkiv, Ukraine, 61002 \\ yelena.tishkovets@gmail.com \\ ${ }^{1}$ Department of Pediatric Dentistry and Implantology \\ Kharkiv National Medical University \\ 4 Nauky ave., Kharkiv, Ukraine, 61022
}

\begin{abstract}
Early diagnosis of dental caries in children is difficult. This fact is applied to children with Down syndrome. In order to identify predictors of dental diseases, a crystallographic method is widely used for studying oral fluid.

The aim of the work is to evaluate the mineralizing potential of oral fluid in children with Down syndrome before and after the course of preventive measures.

Material and methods. We examined oral fluid in children with Down syndrome. Children and adolescents at the age of 8 months to 17 years $(n=21)$ were divided into groups depending on the age and the level of caries intensity. The results were compared with the data of 55 children without chromosomal pathology.

Results. The group of children with Down syndrome (MG), during the initial examination includes type II - 11 people $(53 \%)$ and type III -7 people (33\%) microcrystallization of saliva, which generally corresponds to the situation in the group of children without chromosomal pathology (CG), where type II included $62 \%$ (34 people) and type III - $22 \%$ (12 people). The average value of the mineralizing potential of saliva in the main group was $2.78 \pm 0.22$, and in the control group $-2.89 \pm 0.17$.

Conclusions. After preventive measures during the re-examination of children with Down syndrome, there was a tendency to an increase in the level of parameters of the mineralizing potential of saliva while maintaining this level after 6 months.

Keywords: dental caries, children, Down syndrome, mineralizing potential, preventive measures.

\section{Introduction}

Dental caries in children is one of the most common infectious diseases [1]. It is difficult to diagnose caries in children at an early stage [2]. This fact is applied to children with Down syndrome. Working with children in this category is significantly complicated for the dentist due to the peculiarities of mental development and emotional instability of the child in a dental clinic [3].

In order to identify predictors of dental diseases, oral fluid is widely studied as a biological substrate [4]. One of the methods widely used in dentistry is a crystallographic method for studying biological substrates. The method is based on the evaluation of the micromorphological picture of dried biological fluids, which reflects the processes in the human body. In case of pathological conditions, the crystal-forming properties of the body fluid are changed [5].
\end{abstract}

DOI: $10.21303 / 2504-5679.2020 .001330$ 
As a diagnostic criterion for dental diseases, structural changes in crystals of mixed saliva are examined [6]. One of the main functions of mixed saliva is its mineralizing potential - providing mechanisms maintaining the dynamic balance of mineral components in the oral fluid [7].

Highly informative crystallographic research methods, the relative availability of diagnostic material, non-invasiveness, as well as their cost-effectiveness, allow to use these research methods in paediatric dentistry for rapid and early diagnosis of dental diseases [8].

The aim of the study is to evaluate the mineralizing potential of oral fluid in children with Down syndrome before and after the course of preventive measures.

\section{Materials and methods}

The study was conducted on the base of the University Dental Center of Kharkiv National Medical University during 2017-2018.

We examined oral fluid of 76 patients at the age of 8 months to 17 years. The main group consisted of patients with Down syndrome $(n=21, M G)$. The control group $(n=55, C G)$ consisted of conditionally healthy children without chromosomal pathology. Children and adolescents were divided into groups depending on the level of caries intensity (UIC, P.A. Leus, 1996).

All the examined children and their parents have been informed of the aim of the study and the methods to be applied. Parents have given written consent to participate in the study.

The study project was approved by the Ethics and Bioethics Commission (protocol No. 4 2017 of 07/06/2017) and was carried out in accordance with the Declaration of Helsinki specifying the procedure of biomedical human research.

Microcrystallization of saliva (MCS) was determined according to P. A. Leus [9]. The oral fluid was taken in two hours after food intake. Using a sterile plastic spoon, unstimulated saliva was collected from the sublingual area of the oral cavity. Three drops of oral fluid were applied to a glass slide, which had previously been degreased and numbered, and dried at $18-25^{\circ} \mathrm{C}$ in a horizontal position. The obtained results were studied in the light of the monocular microscope "BIOLAM C1". Pictures of the crystals were obtained through the photomicrographic attachment (PMA-9). Microscopy of the dried drops determined the type of micro-installation of saliva and evaluated the mineralizing potential of saliva (MPS) expressed in points.

In order to increase the resistance of teeth hard tissues, a set of preventive measures was assigned for each child with Down syndrome (according to the scheme), namely the use of a combination of toothpastes and foams for oral care containing calcium, fluorine and milk enzymes (lactoperoxidase, lactoferrin, glucose oxidase), a remineralization gel for home use, which is a source of easily digestible calcium, phosphorus and magnesium compounds, and a gel containing amine fluoride, sodium fluoride, chlorhexidine and betaine.

The accumulation, correction, systematization of the initial information and visualization of the obtained results were carried out in Microsoft Office Excel 2007 spreadsheets. Statistical analysis was performed using STATISTICA 6.1 (developed by StatSoft.Inc).

Nominal data were described with absolute values and percentages. The average and standard deviation of the variables were calculated. For related samples, Student's t-test was used for paired cases.

\section{Results}

In the main group, among children with intact teeth, type II microcrystallization prevails in 8 people $(38 \%)$. The higher the activity of the carious process, the greater the proportion of children with type III microcrystallization of saliva (Fig. 1).

Among children of the control group, type I microcrystallization is found only in children with intact teeth in 5 people $(9 \%)$ and children with low caries activity in 4 people $(7 \%)$. In the group with a very high carious process activity, type III microcrystallization significantly prevails in 7 people (13\%) (Fig. 2).

According to the results of the microcrystallization test of saliva, it was found that in the group of children with Down syndrome (MG), during the initial examination, type II in 11 people $(53 \%)$ and type III in 7 people (33\%) microcrystallization of saliva prevail, which generally 
corresponds to the situation in the group of children without chromosomal pathology (CG), where type II was $62 \%$ ( 34 people), and type III - $22 \%$ (12people).

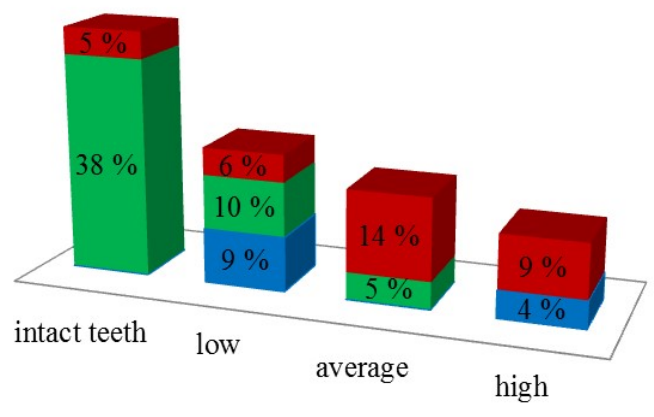

-Type I $\quad$ Type II $\quad$ Type III

Fig. 1. Distribution by types of microcrystallization of saliva at different levels of the carious process activity among children with Down syndrome (MG)

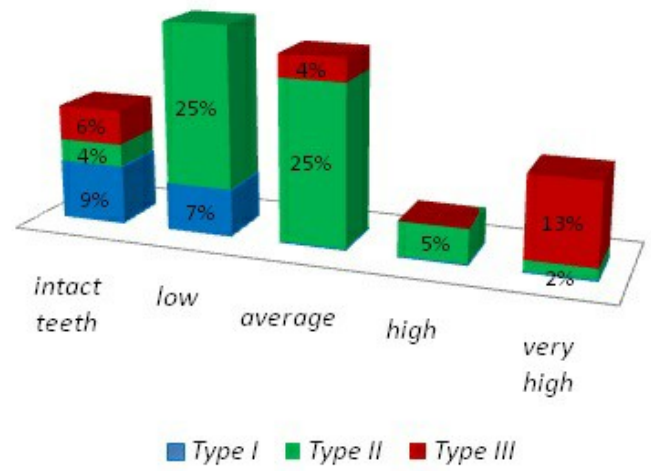

Fig. 2. Distribution by types of microcrystallization of saliva at different levels of the carious process activity among children in the control group

Mineralizing potential of saliva was evaluated as very low with an average value 0 to 1.0 points; low - with 1.1 to 2.0 points; satisfactory - with 2.1 to 3.0 points; high - with 3.1 to 4.0 points; very high - with 4.1 to 5.0 points.

In the patients of the main group (MG), the MPS values are as follows: a very low level was detected in 2 people (10\%); low - in 4 people $(19 \%)$; satisfactory - in 7 people $(33 \%)$; high - in 8 people (38 \%) (Fig. 3$)$.

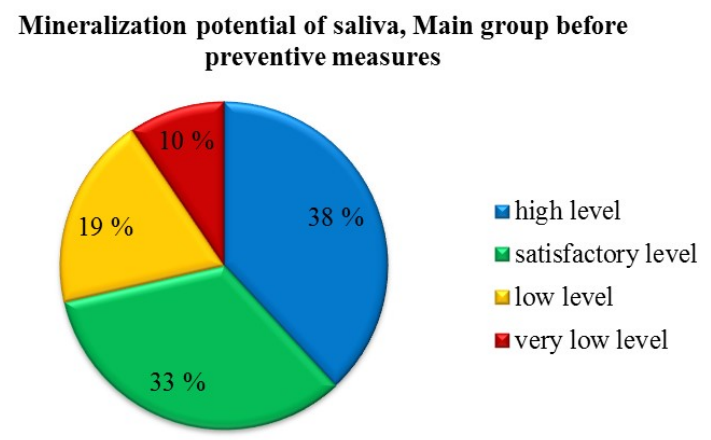

Fig. 3. Mineralization potential of saliva in the main group (MG) before preventive measures

In the patients of the control group (CG), a very low mineralizing potential of saliva was detected in 1 person ( $2 \%$ ); low - in 3 people (5\%); satisfactory MPS - in 40 people (73\%); high in 9 people (16\%); very high - in 2 people (4 \%) (Fig. 4). 


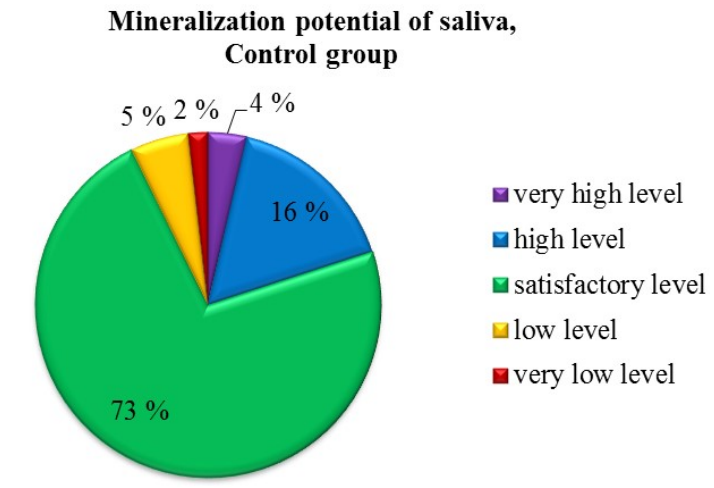

Fig. 4. Mineralization potential of saliva in the control group (CG)

The average value of the mineralizing potential of saliva in the main group was $2.78 \pm 0.22$, and in the control group $-2.89 \pm 0.17$.

Before preventive measures in the group of children with Down syndrome (MG), the following results were obtained: type I of the microcrystallization test of saliva consists of $14 \%$ (3 people), type II - $53 \%$ (11 people) and type III - $33 \%$ (7 people) (Fig. 5).

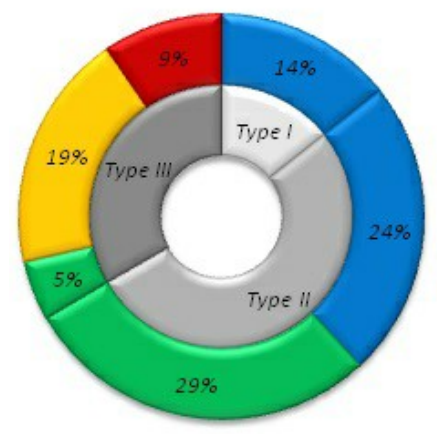

$$
\begin{aligned}
& \checkmark \text { Typel } \\
& \text { ⿴囗十 Type II } \\
& \text { - Type III } \\
& \text { - highlevel } \\
& \text { - satisfactory level } \\
& \text { alowlevel } \\
& \text { - very low level }
\end{aligned}
$$

Fig. 5. Distribution by MCS types and MPS categories in a group of children with Down syndrome $(\mathrm{MG})$ before caries preventive measures

After preventive measures (re-examination) we can see increasing of type I level of microcrystallization of saliva and was $38 \%$ (8 people). MCS type III was not detected Fig. 6.

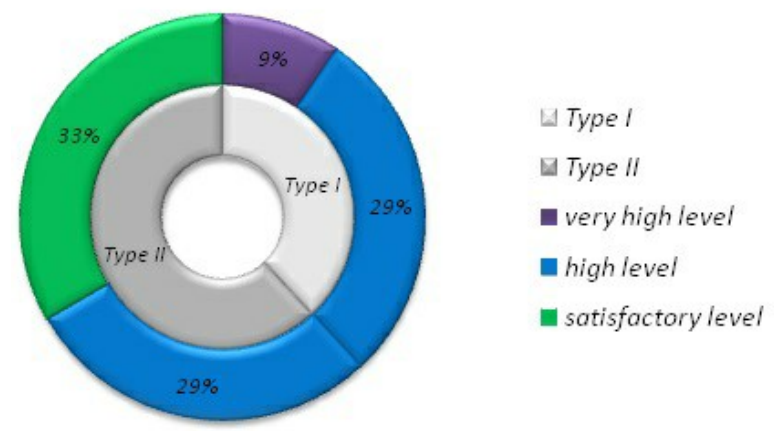

Fig. 6. Distribution by MCS types and MPS categories MPS in a group of children with Down syndrome after preventive measures

According to the results 6 months after - it was found that type I consists of $29 \%$ (6 people), type II - $71 \%$ (15 people) (Fig. 7).

After preventive measures, the examination of children of the main group (re-examination), the percentage of type I microcrystallization of saliva increased by more than 2.5 times and was $38 \%$ (8 people), and MCS type III was not detected. During the examination of children with Down 
syndrome (MG), 6 months after the course of preventive measures, there was a decrease in the component of type I microcrystallization of saliva (up to $29 \%$ (6 people)) and an increase in the level of the component of MCS type II (up to $71 \%$ (15 people)), MCS type III was not detected (Fig. 8).

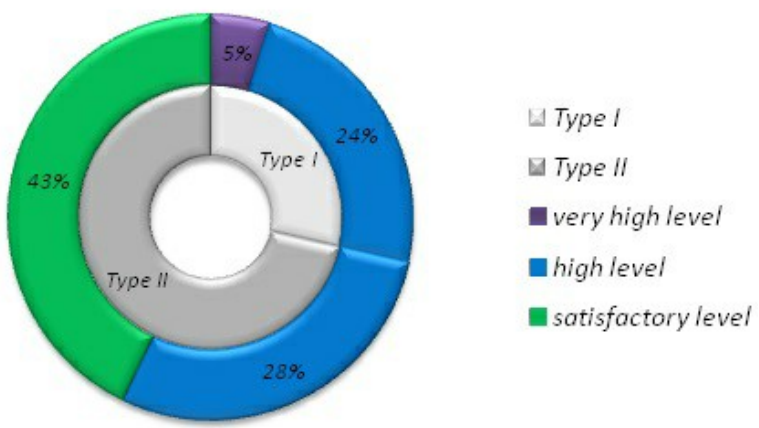

Fig. 7. Distribution by MCS types and MPS categories in a group of children with Down syndrome (MG) 6 months after caries preventive measures

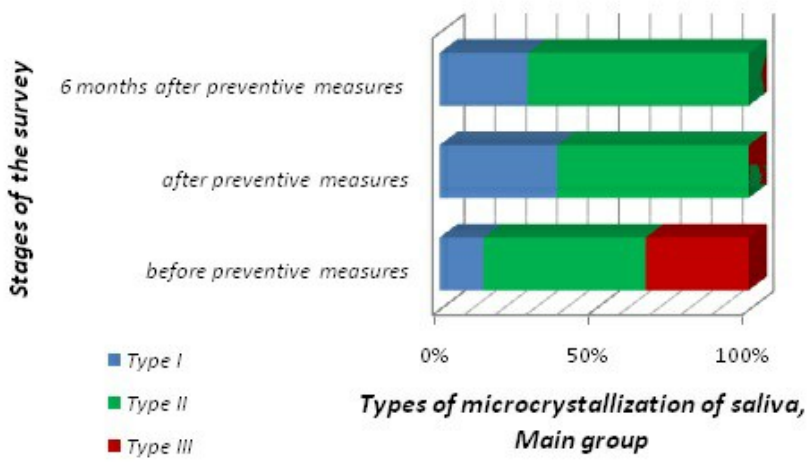

Fig. 8. Distribution by type of microcrystallization of saliva in a group of children with Down syndrome $(\mathrm{MG})$ at different stages of the examination

Changes in the oral fluid in children with Down syndrome (MG) at the examination stages (before the course of prevention, after the course of preventive measures and 6 months after the caries preventive measures) are presented in Table 1.

Table 1

Distribution by MCS types and mineralizing potential of saliva $(\mathrm{M} \pm \mathrm{m})$

\begin{tabular}{ccccc}
\hline \multirow{2}{*}{ Parameter } & \multicolumn{3}{c}{ Main group, $\mathbf{n = 2 1}$} & Control group, \\
\cline { 2 - 4 } & $\begin{array}{c}\text { Before preventive } \\
\text { measures }\end{array}$ & $\begin{array}{c}\text { After preventive } \\
\text { measures }\end{array}$ & $\begin{array}{c}\mathbf{6} \text { months after } \\
\text { preventive measures }\end{array}$ & $\begin{array}{c}\text { I }-16 \% \\
\text { MCS, } \%\end{array}$ \\
I $-14 \%$ & $\mathrm{I}-38 \%$ & $\mathrm{I}-29 \%$ & $\mathrm{II}-62 \%$ \\
& $\mathrm{II}-53 \%$ & $\mathrm{II}-62 \%$ & $\mathrm{II}-71 \%$ & $\mathrm{III}-22 \%$ \\
MPS, points & $\mathrm{III}-33 \%$ & $\mathrm{III}-0 \%$ & $3.35 \pm 0.17 *$ & $2.89 \pm 0.17$
\end{tabular}

Note: ${ }^{*}-p<0.05$ is statistically reliable compared with parameters of caries preventive measures

The level of parameters of the mineralizing potential of saliva after preventive measures increased (2.78 \pm 0.22 to $3.48 \pm 0.2)$. These results indicated the maintenance of this level (3.35 \pm 0.17$)$.

\section{Discussion}

Unfortunately, in our study, due to the small sample size (this is due to a number of ethical obstacles), we did not always succeed in analyzing the statistical significance of the obtained re- 
sults, as well as assessing the prognostic significance of this study parameter to evaluate the effectiveness of the proposed complex of preventive measures.

However, the problem of early childhood caries exists and various approaches to its solution are needed.

The subject of our study is relevant in pediatric dentistry and meets the requirements of modern scientific research. Further study of the pathogenetic mechanisms of dental caries in children with Down syndrome, by identifying disease predictors, will expand the range of preventive measures used to prevent dental diseases.

Our study requires further analysis of the results with an increase in the number of study participants and the observation period. It would also be interesting to investigate the effectiveness of the proposed complex of preventive measures adapted to the behaviour of children with Down syndrome and extrapolate the study data to young children without chromosomal pathology.

The studies reflecting the relationship between the body state and the oral fluid properties are widely represented in the literature. Therefore, the assessment of oral fluid, as a non-invasive research method, is a promising direction in the prevention of dental diseases for young children with and without chromosomal pathology.

Properties of saliva are extremely important for general oral cavity conditions especially in children $[10,11]$. According to the literature, different factors could be important for development of pathological conditions: individual anatomy [12], environment [13], infectious disease [14, 15], habits [16], immune processes [17, 18] and other.

The recent studies have proved the influence of internal factors and environmental factors on the mineralizing potential of human saliva etc $[19,20]$. The structural properties of mixed saliva are directly affected by general somatic diseases [21, 22], such as gastrointestinal diseases, bronchopulmonary pathology, diabetes mellitus, blood diseases, immune disturbance, etc [23, 24].

Adverse factors include acidification or alkalinisation of saliva, the addition of electrolytes, carbohydrate intake etc [25]. Thus, fluctuations in the $\mathrm{pH}$ and concentration of electrolyte components of saliva above or below the physiological norm can change the physical and chemical composition of saliva, shift the ratio of structures and, consequently, decrease the resistance of micelles or disruption of micelle formation processes [26], even anatomical peculiarities [27].

It is proved that such changes in the physical and chemical properties of the oral fluid can lead to a cariogenic situation or to a situation that will contribute to the formation of mineralized dental deposits in the oral cavity [28].

Considering the above mentioned, we can assume that the biophysical and chemical properties of the oral fluid of children and adolescents with Down syndrome also undergo changes.

After examining children with Down syndrome, studying the medical history, collecting anamnestic data from parents, we defined that in addition to chromosomal changes every child with Down syndrome has any concomitant pathology.

In addition, nutritional characteristics, bad habits, difficulties in hygienic procedures (sometimes a total absence of oral hygiene) are additional factors that affect the composition and properties of the oral fluid.

An individual prevention program was developed for each child, including parental hygienic education. The choice of the proposed combinations of prevention means is due to the peculiarities of the mental development of children with Down syndrome, their emotional instability when interacting not only with the dentist, but also with their parents when performing hygienic manipulations in the oral cavity. The proposed combinations of prevention measures are aimed at optimizing the work of the dentist, as well as contribute to a more qualitative procedure of oral hygiene at home.

The implementation of the proposed preventive measures, which were carried out by the dentist in the clinic and at home, revealed an improvement in the oral hygiene of the child, an increase in the mineralizing potential of saliva which is consistent with the data of other authors [29, 30].

\section{Conclusions}

After preventive measures, the examination of children with Down syndrome (re-examination), the percentage of type I microcrystallization of saliva increased by more than 2.5 times, and 
MCS type III was not detected. During the examination of children with Down syndrome (MG), 6 months after the course of preventive measures, there was a decrease in the component of type I microcrystallization of saliva and an increase in the level of the component of MCS type II, MCS type III was not detected.

In addition, there is a tendency to increase the level of parameters of the mineralizing potential of saliva after preventive measures while maintaining this level after 6 months.

Early detection of risk factors for caries in children using non-invasive diagnostic methods, timely prevention of dental diseases, and hygienic awareness of parents raising a child with Down syndrome can prevent the development of dental diseases in a child.

\section{Conflict of interest}

The authors declare that they have no conflicts of interest.

\section{References}

[1] Tschoppe, P., Wolf, O., Eichhorn, M., Martus, P., Kielbassa, A. M. (2011). Design of a randomized controlled double-blind crossover clinical trial to assess the effects of saliva substitutes on bovine enamel and dentin in situ. BMC Oral Health, 11 (1). doi: http://doi.org/10.1186/1472-6831-11-13

[2] Kindrat, G. (2011). Pathogenetic mechanism of paediatric caries. Halytskyi Medical Annals, 18 (3), $122-124$.

[3] Nazaryan, R., Iskorostenskaya, O., Gorenskaya, O., Volkova, N., Gargin, V. (2018). Interrelation of the gene 4DKN1A (RS 1801270) polymorphic state and level of development of caries in children with Down syndrome. Georgian Med News, 2 (275), 112-116.

[4] Avetikov, D., Bondarenko, V., Danylchenko, S., Pronina, E., Stavytskyi, S. (2014). Energy metabolism disorders in rat salivary glands tissues in connection with chronic sodiumnitrate intoxication. Georgian Med News, 3 (237), 76-79.

[5] Kazakova, R. (1999). Using the structure of oral fluid in diagnosing dental caries. Materials of I (VIII) Congress of the Association of Ukrainian Dentists, 72-73.

[6] Tkachenko, P., Starchenko, I., Belokon, S., Gurzhiy, Y., Starchenko, O. (2016). Clinical and tactical approaches in the diagnosis of malignant tumors of maxillofacial area in children. New Armenian Medical Journal, 10 (3), 27-33.

[7] Nazaryan, R., Kryvenko, L. (2017). Salivary oxidative analysis and periodontal status in Ukrainian children with atopy. Interventional Medicine \& Applied Science, 9 (4), 199-203. doi: http://doi.org/10.1556/1646.9.2017.32

[8] Cunha-Cruz, J., Scott, J., Rothen, M., Mancl, L., Lawhorn, T., Brossel, K., Berg, J. (2013). Salivary characteristics and dental caries: Evidence from general dental practices. The Journal of the American Dental Association, 144 (5), e31-e40. doi: http:// doi.org/10.14219/jada.archive.2013.0159

[9] Leus, P. (1997). Clinical and experimental study of pathogenesis, pathogenetic conservative therapy and prevention of dental caries, 30 .

[10] Tkachenko, P., Pankevych, A., Kolisnyk, I., Gogol, A. (2018). Diagnostic information of computed tomography of the upper jaw in patients required implantrehabilitation. Wiad Lek, 71 (9), 1645-1652.

[11] Avetikov, D., Bukhanchenko, O., Ivanytskyi, I., Aipert, V., Steblovskyi, D. (2018). Perspectives for applying the additional study methods for diagnostics optimization of postoperative hypertrophic scars of the head and neck. Wiad Lek, 71 (3 pt 1), 470-473.

[12] Tkachenko, P., Belokon, S., Dobroskok, V., Korotich, N., Lohmatova, N. (2017). Informativeness of ultrasonography and sialodenography in active clinical course of chronic parenchymatous parotitis in children. New Armenian Medical Journal, $11(3), 37-42$.

[13] Kovach, I., Kravchenko, L., Khotimska, Y., Nazaryan, R., Gargin, V. (2017). Influence of ozone therapy on oral tissue in modeling of chronic recurrent aphthous stomatitis. Georgian Med News, 264, 115-119.

[14] Kozko, V. M., Bondarenko, A. V., Gavrylov, A. V., Shevchenko, O. S., Gargin, V. V. (2017). Pathomorphological peculiarities of tuberculous meningoencephalitis associated with HIV infection. Interventional Medicine and Applied Science, 9 (3), 144-149. doi: http://doi.org/10.1556/1646.9.2017.31

[15] Lytvynenko, M., Shkolnikov, V., Bocharova, T., Sychova, L., Gargin, V. (2017). Peculiarities of proliferative activity of cervical squamous cancer in HIV infection. Georgian Med News, 270, 10-15.

[16] Lytvynenko, M., Bocharova, T., Zhelezniakova, N., Narbutova, T., Gargin, V. (2017). Cervical transformation in alcohol abuse patients. Georgian Med News, 271, 12-17.

[17] Avilova, O., Shyian, D., Marakushin, D., Erokhina, V., Gargin, V. (2018). Ultrastructural changes in the organs of the immune system under the influence of xenobiotics. Georgian Med News, 279, 132-137. 
[18] Nazaryan, R., Kryvenko, L., Gargin, V. (2017). The role of nitric oxide synthase in the modulation of the immune response in atopic disease. The New Armenian Medical Journal, 11 (2), 52-57.

[19] Smoliar, N. (2005). Peculiarities of microcrystallization of oral fluid in preschool. Annals of Dentistry, 4, 70-73.

[20] Tayab, T., Rai, K., Kumari, A. (2012). Evaluating the physicochemical properties and inorganic elements of saliva in caries-free and caries-active children. An in vivo study. European Journal of Paediatric Dentistry, 13 (2), 107-112.

[21] Avilova, O., Marakushin, D., Nakonechna, O., Gargin, V. (2018). Microscopic features of the spleen under the influence of laproxides. Georgian Med News, 276, 163-167.

[22] Denga, O., Pyndus, T., Gargin, V., Schneider, S. (2017). Influence of metabolic syndrome on condition of microcirculatory bed of oral cavity. Georgian Med News, 273, 99-104.

[23] Shmulich, V., Uryvayva, M., Lupaltsova, O., Staruseva, V., Rybka, O., Shmulich, O., Kryvenko, L. (2015). Comparative analysis of the role of domestic allergens in atopic dermatitis etiology in children. Inter colleges, 2 (3), 205-211.

[24] Avetikov, D., Loza, K., Starchenko, I., Loza, E., Marushchak, M. (2015). Experimental-morphological substantiation of expediency to use the skin glue "Dermabond" for postoperative wound closure. Georgian Med News, 244-245, 90-93.

[25] Alekseeva, V., Lupyr, A., Urevich, N., Nazaryan, R., Gargin, V. (2019). Significance of Anatomical Variations of Maxillary Sinus and Ostiomeatal Components Complex in Surgical Treatment of Sinusitis. Novosti Khirurgii, 27 (2), 168-176. doi: http:// doi.org/10.18484/2305-0047.2019.2.168

[26] Wang, X., Wang, Y., Wang, K., Ren, Q., Li, H., Zheng, S. et. al. (2018). Bifunctional anticaries peptides with antibacterial and remineralizing effects. Oral Diseases, 25 (2), 488-496. doi: http://doi.org/10.1111/odi.12990

[27] Kovach, I., Kravchenko, L., Gargin, V. (2016). Morphofunctional peculiarities of tissue of oral cavity in chronic recurrent aphthous stomatitis with therapeutical correction. Inter Collegas, 3 (3), 146-149. doi: http://doi.org/10.35339/ic.3.3.146-149

[28] Kovach, I., Buniatian, K., Makarevych, A., Verbyts'ka, A., Gargin, V. (2018). Influence of tricalcium silicate on course of traumatic pulpitis. Georgian Med News, 276, 130-134.

[29] Kaskova, L. (2009). The influence of preventive measures on biochemical parameters of oral fluid in children. Ukrainian Dental Almanac, 6, 54-57.

[30] Kachurovska, V. (2003). Changes in the mineralizing function of saliva under the influence of calcium homeopathic compounds. Ukrainian Dental Almanac, 2, 10-12. 